\title{
Erratum
}

\section{Crisomelidi (Coleoptera; Chrysomelidae) del Parco di Montevecchia e della Valle del Curone (Italia, Lombardia, provincia di Lecco) [Leaf beetles (Coleoptera; Chrysomelidae) from Montevecchia and Curone Valley Natural Park (Italy, Lombardy, Lecco)]}

\section{Laura Farina}

A causa di un errore tecnico, nel lavoro originale: I Crisomelidi (Coleoptera; Chrysomelidae) del Parco di Montevecchia e della Valle del Curone (Italia, Lombardia, provincia di Lecco). Natural History Sciences. Atti Soc. it. Sci. nat. Museo civ. Stor. nat. Milano, 2 (2): 61-88. DOI: $10.4081 / n h s .2015 .233$, la figura 13 è stata riprodotta in modo incompleto.

La figura corretta appare qui sotto.

[Due to a technical error, figure 13 in the original paper is not properly displayed.

The correct figure 13 appears below.]
Via A. Stoppani 17/A, 23880 Casatenovo (LC), Italia

E-mail: lau.farina@libero.it

(C) 2016 Laura Farina

Received: 9 June 2016

Accepted for publication: 9 June 2016

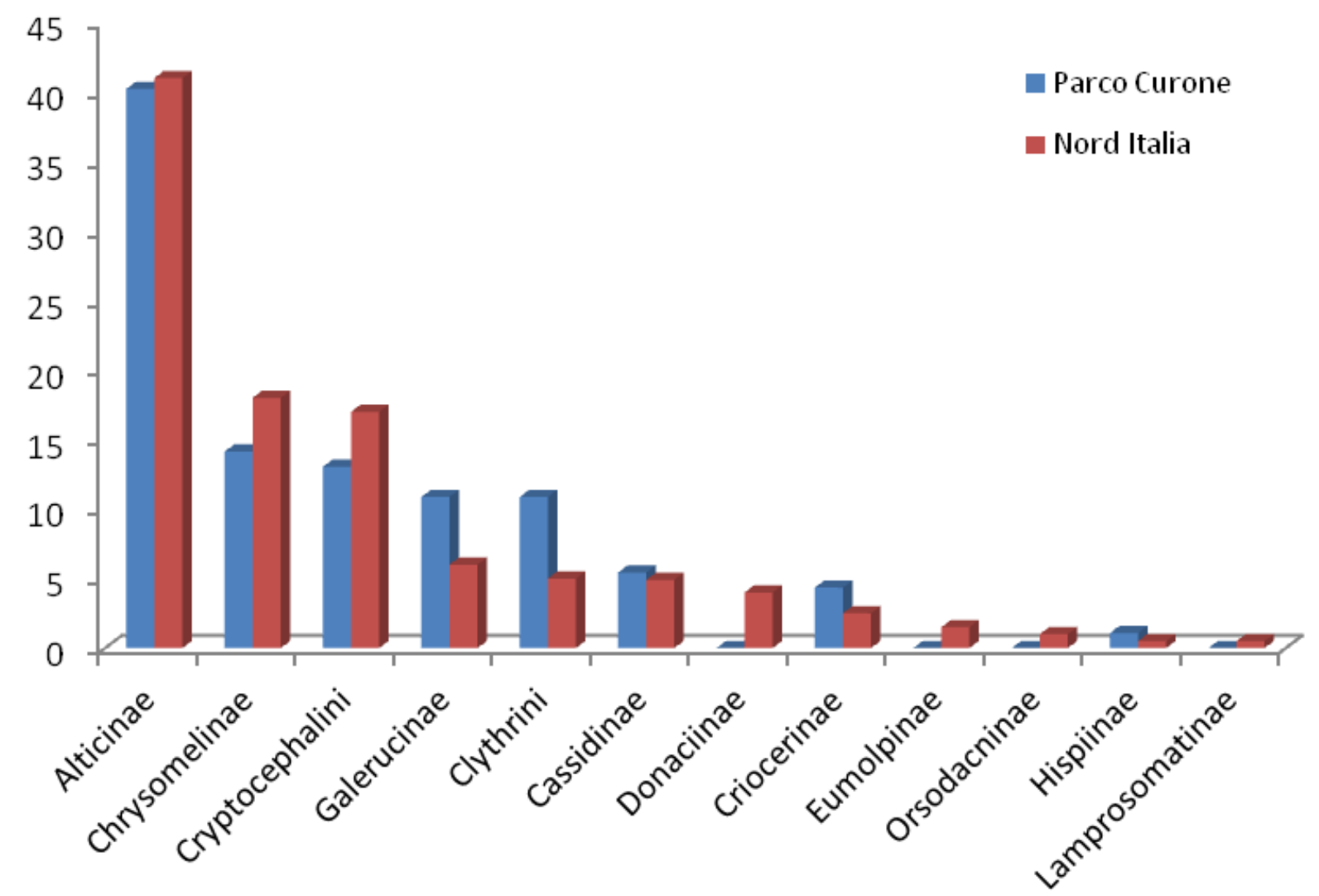

Fig. 13 - Distribuzione percentuale per sottofamiglie delle specie rilevate confrontata con i dati relativi al nord Italia (Löbl \& Smetana, 2010). 